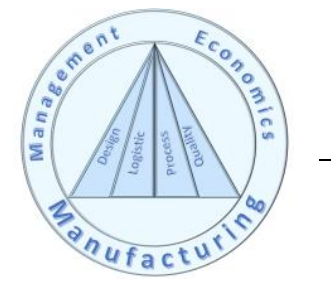

\title{
INFLUENCE OF TECHNOLOGICAL PARAMETERS ON THE AWJ PROCESS PERFORMANCE
}

\author{
Simona-Nicoleta Mazurchevici, Ramona Iuliana Popa, Daniel Mărguță \\ "Gheorghe Asachi” Technical University of Iasi, Department of Machine Manufacturing Technology \\ Blvd. Mangeron, No. 59A, 700050, Iasi, Romania
}

Corresponding author: Ramona Iuliana Popa, popa_ramona83@yahoo.com

\begin{abstract}
The present study aims to perform a comparative analysis of the technological parameters influence on the output parameters for two biodegradable polymeric materials, Arbofill Fichte and Arboblend V2 Nature. The varied input parameters during abrasive water jet cuuting (AWJ) were water jet pressure, traverse speed and abrasive material flow. The quantitative and qualitative output parameters proposed are the amount of material removed (MR) and the inclination angle - $\alpha^{\circ}$ of the resulted surfaces. The measured MR and $\alpha^{\circ}$ values highlighted the fact that they fall within the admissible parameters, so that the obtained parts by cutting the Arbofill Fichte and Arboblend V2 Nature samples can be used in industrial applications that require this type of processing and more. Was also achieved the optimization of the technological parameters used for processing according to the next criteria: minimum inclination angle and minimum amount of material removed.
\end{abstract}

Key words: AWJ, biodegradable polimers, MR, $\alpha^{\circ}$, optimization.

\section{INTRODUCTION}

Polymers have developed as an alternative to metallic materials, because they are ease of processing, have low density and cost. But in a short time these advantages were no longer enough, due to the fact that the environment began to be suffocated by their widespread use, so researchers start to look for solutions to minimize / eliminate as much as possible this disadvantage. In this context, biodegradable polymeric materials have experienced an extraordinary progress. This new class of polymers, in addition to biodegradability, also comes with the advantage of energy savings, due to much lower processing temperatures than polymers based on fossil resources, $[1,2]$. However, the thermal sensitivity of biodegradable polymers raises limitations, being possible to use only technologies that work with low temperatures or that use cooling media. AWJ - water jet cutting with abrasive is part of modern unconventional manufacturing processes, can be realised with or without abrasive mixture and is a very good alternative to other traditional cutting technologies. Thus, the biodegradable polymeric materials are not subjected to the heating process, due to the water that acts as a cooling medium but also to the relatively short processing time, thus being possible to obtain parts without structural changes of the material after processing.

The quality of the surfaces processed by this technological process is influenced by several factors as: material thickness; its physico-chemical properties and process parameters - pressure, cutting speed, radius correction, technical condition of the machine and especially of the nozzles.

Many investigations have been conducted to understand the influence of process parameters on cutting performance elements, such as cut width, taper and roughness of cut surfaces. Cutting geometry is a feature of major interest in abrasive water jet cutting. As shown in figure 1, by cutting with water jet will form a slot with inclined side surfaces, so that in the input area of the jet the slot is wider, $L_{i}$, and in the output area is narrower, $L_{o}$. To define this cut characteristic, either the taper of the slit or the inclination angle the slit, $\alpha^{\circ}$, are used. In general, this method achieves very good cutting surface qualities compared to other cutting processes. A very important aspect is the inclination of the surfaces of the cut area which refers to the inclination from the area of entry of the jet into the material to its exit from the material. This inclination occurs due to the different exposure time to erosion by contact with the water jet of the material areas from the entrance to the exit of the material. According to the inclination of the cut areas, the following shapes of the resulting joint are distinguished: inclined in $V$ - it appears where the tip of the cut is wider in the part of the jet penetration than at 
the base of the material. This is the result of the fact that the jet spends enough time in an area to erode the material more than at the base. The jet tends to erode the edges; reverse slope - occurs where the tip is narrower than the base. This tends to happen with soft materials when the material is eroded quickly or when cutting is very slow. As the water jet expands as it moves farther from the nozzle, it removes more material; sloping barrel - is when the middle is wider than the top or base area. This shape tends to occur in very thick materials; inclined rhomboidal or trapezoidal - is actually the $\mathrm{V}$ shape that has been tilted, because the nozzle does not make right angles with the material. This inclined shape is actually very small, being very little visible to the naked eye. Its appearance is made by increasing the cutting speed or in the case of thin materials, by stacking them, [3]. In the present manuscript, the shape obtained after cutting Arbofill Fichte and Arboblend V2 Nature materials was inclined in $\mathrm{V}$.

Dimensional and geometric accuracy is an essential qualitative characteristic to be obtained after cutting parts, also the amount of material removed is an important qualitative characteristic that is strictly influenced by the quality characteristics of the material.

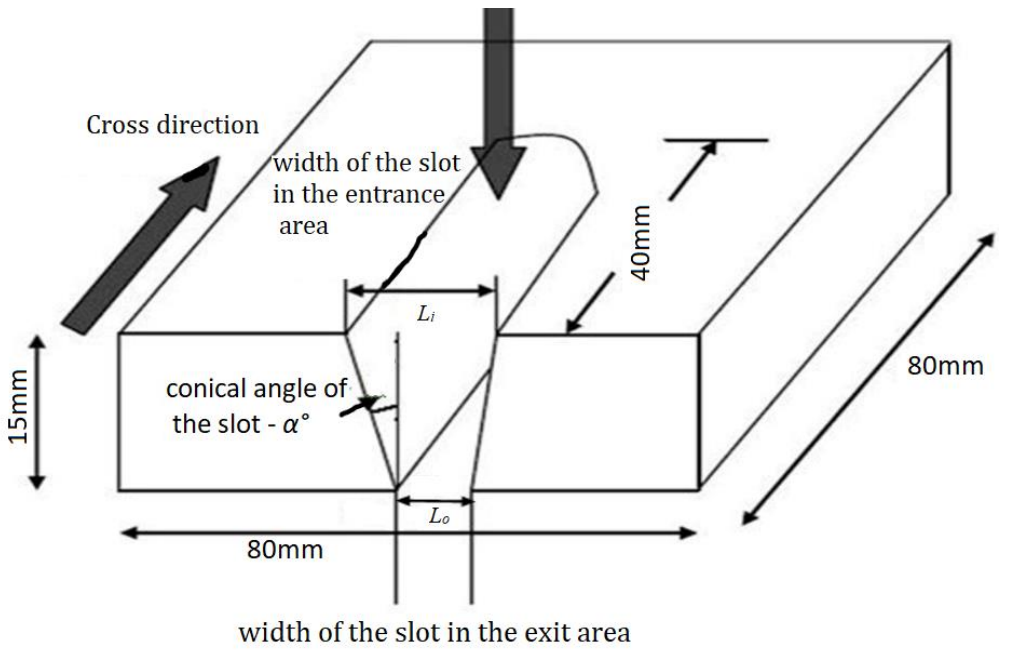

Fig. 1. Slot geometry resulting from water jet cutting, [4]

The purpose of this paper is to highlight the influence of technological parameters on the measured / determined parameters, the angle of inclination and the amount of material removed. Also, the study aims to optimize these technological parameters in order to minimize the amount of material removed but also the inclination angle obtained from the processing of biodegradable materials - Arbofill Fichte and Arboblend V2 Nature.

The novelty of this study is given by the selected materials to be cut, which are biopolymer and have not been studied so far. Also, in the research literature the AWJ cutting of biodegradable materials is reduced. The importance of the paper is given by the obtained results, which provide information on the behavior in abrasive water jet processing of Arbofill Fichte and Arboblend V2 Nature, information that can be assimilated for all biodegradable plastics with a structure similar to that of the studied materials - lignin-based polymers.

\section{MATERIALS AND METHODS}

The used materials for injecting the samples were Arboblend V2 Nature and Arbofill Fichte. This biodegradable polimers are produced by Fraunhofer Institute for Chemical Technology (IKT) in colaboration with Tecnaro company (Ilsferd, Germany). The polimers matrix is made of lignin but also contains polylactic acid, biopolyamides, cellulose, bio-polyolefins, natural binders (waxes, resins, oils, etc.) and vegetable fibers, [5].

The injection of samples was realised with SZ800 H industrial injection machine, from the endowment Fine Mechanics laboratory, "Gheorghe Asachi" Technical University of Iasi, Romania. The injection conditions are highlighted in table 1, and were established following a systematic analysis of the AWJ procedure, [6]. The sample size was $(58 \times 48 \times 10) \mathrm{mm}$ and the mold temperature was kept constant at $50^{\circ} \mathrm{C}$.

Table 1. Technological parameters used for obtaining the samples to cut

\begin{tabular}{ccccc}
\hline \multirow{2}{*}{ Biodegradable polimers } & $\begin{array}{c}T_{i n j} \\
{\left[{ }^{\circ} \mathrm{C}\right]}\end{array}$ & $\begin{array}{c}P_{i n j} \\
{[\mathrm{MPa}]}\end{array}$ & $\begin{array}{c}s_{i n j} \\
{[\mathrm{~mm} / \mathrm{s}]}\end{array}$ & $\begin{array}{c}t_{r} \\
{[\mathrm{~s}]}\end{array}$ \\
\hline Arbofill Fichte & 155 & 90 & 80 & 25 \\
\hline Arboblend V2 Nature & 170 & 110 & 90 & 25
\end{tabular}

where: $T_{i n j}$ - injection temperature, $\left[{ }^{\circ} \mathrm{C}\right] ; P_{i n j}$ - injection pressure; $s_{i n j}$ - injection speed; $t_{r}$ - cooling time. 
The cutting of the samples was made with the help of Hydro Jet Eco 0615 equipment, it uses the abrasive water jet cutting -AWJ method. During cutting a series of parameters were kept constant: sample thickness - 10mm; abrasive material - Garnet; sample - machining head distance - 3mm; diameter of the water hole - 0.35mm; focusing tube diameter $-1.02 \mathrm{~mm}$; focusing tube length $-76.2 \mathrm{~mm}$.

The working methodology was according to ANOVA, $2^{3}$ type factorial plan, 8 experiments, varying three selected process parameters $\left(P\right.$ - pressure, $[\mathrm{MPa}] ; v_{f}$ - traverse speed, $[\mathrm{mm} / \mathrm{min}] ; Q$ - debit material abraziv, $[\mathrm{g} / \mathrm{min}])$ on two levels, as can be observed in table 2 .

Table 2. Factorial experimental plan - abrasive water jet cutting

\begin{tabular}{cccc}
\hline \multirow{2}{*}{$\begin{array}{c}\text { No. } \\
\text { crt. }\end{array}$} & \multicolumn{3}{c}{ Input parameters } \\
\cline { 2 - 4 } & $\begin{array}{c}\mathrm{v}_{\mathrm{f},} \\
{[\mathrm{mm} / \mathrm{min}]}\end{array}$ & $\begin{array}{c}\mathrm{Q} \\
{[\mathrm{g} / \mathrm{min}]}\end{array}$ & $\begin{array}{c}\mathrm{P} \\
{[\mathrm{MPa}]}\end{array}$ \\
\hline 1 & 100 & 150 & 100 \\
\hline 2 & 100 & 300 & 100 \\
\hline 3 & 150 & 150 & 100 \\
\hline 4 & 150 & 300 & 100 \\
\hline 5 & 100 & 150 & 150 \\
\hline 6 & 100 & 300 & 150 \\
\hline 7 & 150 & 150 & 150 \\
\hline 8 & 150 & 300 & 150 \\
\hline$P$
\end{tabular}

$P$ - pressure, [MPa]; $v_{f}$ - traverse speed, [mm/min]; Q - abrasive material flow, [g/min].

Three cuts were performed, on the same sample, for each experiment, using the same process parameters (30mm - length and $7 \mathrm{~mm}$ - distance between the cuts. The repeats were performed in order to demonstrate the structural homogeneity of the injected biopolymers into the mold and also the experimental repeatability.

To determine the influence of technological parameters on the measured parameters, the inclination angle of the resulting surface after cutting and the material removed amount, the MiniTab application was used which generates a report in which the following values are specified: for each factor or interaction between factors: DF (freedom degrees), Adj. SS (adjusted sum of squares), Adj. MS (square of adjusted averages), F-Value (Fisher value) and p-Value (if p-Value is less than 0.05 it is estimated that the influence of the factor / interaction is statistically significant).

The steps to follow with the MiniTab application are, [7]:

$\checkmark$ Setting the observed values from performing experiments;

$\checkmark$ Consider the model three factors (A, B, C) and the three interactions (AB, BC and CA);

$\checkmark$ Analysis of the factors variance and obtaining the constant and the coefficients of the generalized linear model;

$\checkmark$ Elimination from the model of factors and interactions with statistically insignificant influence from the generalized linear model;

$\checkmark$ Analysis of the variance of the factors and obtaining the constant and the coefficients of the new generalized linear model;

$\checkmark$ Hierarchy of factors and their interactions according to the influence exerted on the response followed by the experiment. Highlighting the meaning of influences - whether they are directly proportional or inversely proportional to the response.

Optimization of the technological parameters used for processing according to the criteria, minimum inclination angle and minimum material removed, was also achieved.

\section{RESULTS AND DISCUSSION}

\subsection{Influence of technological parameters on the Arbofill Fichte material}

3.1.1. Amount of material removed - MR

The results of the ANOVA analysis on the influence of technological parameters on the amount of material removed are presented in Table 3. The greatest influence is given by the traverse speed - 21.5 Fisher test value followed by pressure (Fisher test value 15.67 ) and abrasive material flow (5.71 value). 
Table 3. The results of the variance analysis by the ANOVA method - MR parameter

\begin{tabular}{lcccc}
\hline Parameter & Freedom degrees & Adj SS & Adj MS & Fisher value \\
\hline Pressure [MPa] & 1 & 0.004545 & 0.004545 & 15.67 \\
\hline Traverse speed [mm/min] & 1 & 0.006237 & 0.006237 & 21.5 \\
\hline Abrasive material flow [g/min] & 1 & 0.001657 & 0.001657 & 5.71 \\
Error & 4 & 0.00116 & 0.00029 & \\
\hline Total & 7 & 0.013599 & &
\end{tabular}

where: Adj SS - Adjusted Sums of Squares; Adj MS - Adjusted Mean Squares.

The linear matrix model of the technological parameters influences on the amount of material removed is given by equation (1):

$M R=0.43371+\left[\begin{array}{c}-0.02384 \\ 0.02384\end{array}\right] \cdot P+\left[\begin{array}{c}0.0279 \\ -0.0279\end{array}\right] \cdot v_{f}+\left[\begin{array}{c}-0.0144 \\ 0.0144\end{array}\right] \cdot Q,[\mathrm{~g}]$

where $\mathrm{P}$, vf and $\mathrm{Q}$ are the two-dimensional vectors of pressure, feed rate and abrasive material flow, respectively:

$Q=\left[\begin{array}{l}100 \\ 150\end{array}\right], v_{f}=\left[\begin{array}{l}100 \\ 150\end{array}\right]$ și $Q=\left[\begin{array}{l}150 \\ 300\end{array}\right]$

The minimum value of the amount of material removed is $368 \mathrm{~g}$ obtained under the next conditions: $\mathrm{P}=100$ $\mathrm{MPa} ; \mathrm{Vf}=150 \mathrm{~mm} / \mathrm{min}$ and $\mathrm{Q}=150 \mathrm{~g} / \mathrm{min}$. The average amount of material removed from the matrix model is 0.433 [g].

The influence of the technological parameters on the removed material quantity is illustrated graphically in figure 2. The Q parameter decreases with the decrease of the pressure and the abrasive material flow; it also decreases with increasing of traverse speed.

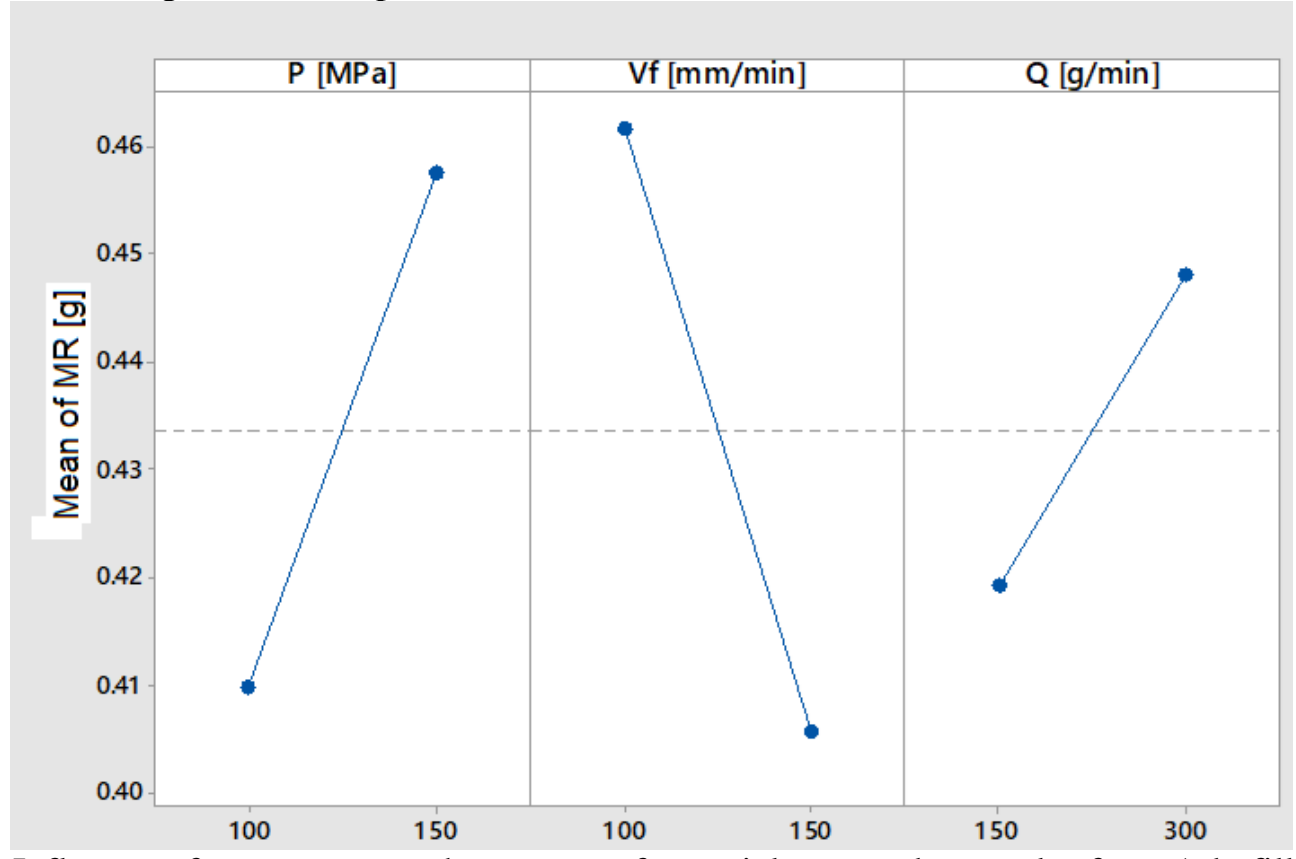

Fig. 2. Influence of parameters on the amount of material removed - samples from Arbofill Fichte

\subsubsection{Angle of inclination of the cutted surface $-\alpha^{\circ}$}

The results of the ANOVA analysis on the technological parameters influence on the inclination angle of the resulting surfaces from are shown in table 4 . The most pronounced influence on the inclination angle is exerted by the pressure parameter (Fisher test value - 3.84), followed by the abrasive material flow parameter, (Fisher test value - 1.66). 
Table 4. The results of the variance analysis by the ANOVA method - inclination angle of the machined surface $\left(\alpha^{\circ}\right)$

\begin{tabular}{lcccc}
\hline Parameter & Freedom degrees & Adj SS & Adj MS & Fisher value \\
\hline Pressure [MPa] & 1 & 0.0431 & 0.0431 & 3.84 \\
\hline Traverse speed [mm/min] & 1 & 0.01279 & 0.01279 & 1.14 \\
\hline Abrasive material flow [g/min] & 1 & 0.01869 & 0.01869 & 1.66 \\
\hline Error & 4 & 0.04491 & 0.01123 & \\
\hline Total & 7 & 0.1195 & &
\end{tabular}

where: Adj SS - Adjusted Sums of Squares; Adj MS - Adjusted Mean Squares.

The linear matrix model of the technological parameters influence on the inclination angle is given by the (2) relation:

$\alpha=0.6201+\left[\begin{array}{c}-0.0734 \\ 0.0734\end{array}\right] \cdot P+\left[\begin{array}{c}-0.04 \\ 0.04\end{array}\right] \cdot v_{f}+\left[\begin{array}{c}0.0483 \\ -0.0483\end{array}\right] \cdot Q,\left[{ }^{\circ}\right]$

where $\mathrm{P}$, vf and Q are the two-dimensional vectors of pressure, traverse speed and abrasive material flow, respectively:

$P=\left[\begin{array}{l}100 \\ 150\end{array}\right], v_{f}=\left[\begin{array}{l}100 \\ 150\end{array}\right]$ and $Q=\left[\begin{array}{l}150 \\ 300\end{array}\right]$

The minimum inclination angle for the above model is $\alpha=0.458^{\circ}$ obtained for the following values of the technological parameters: $\mathrm{P}=100 \mathrm{MPa} ; \mathrm{Vf}=100 \mathrm{~mm} / \mathrm{min}$ and $\mathrm{Q}=300 \mathrm{~g} / \mathrm{min}$. The mean value of the model is $\alpha=0.62\left[^{\circ}\right]$.

The graphical representation of the technological parameters influence on the inclination angle is presented in figure 3. The inclination angle decreases with the reduction of the pressure and the traverse speed; it also decreases with increasing of abrasive material flow.

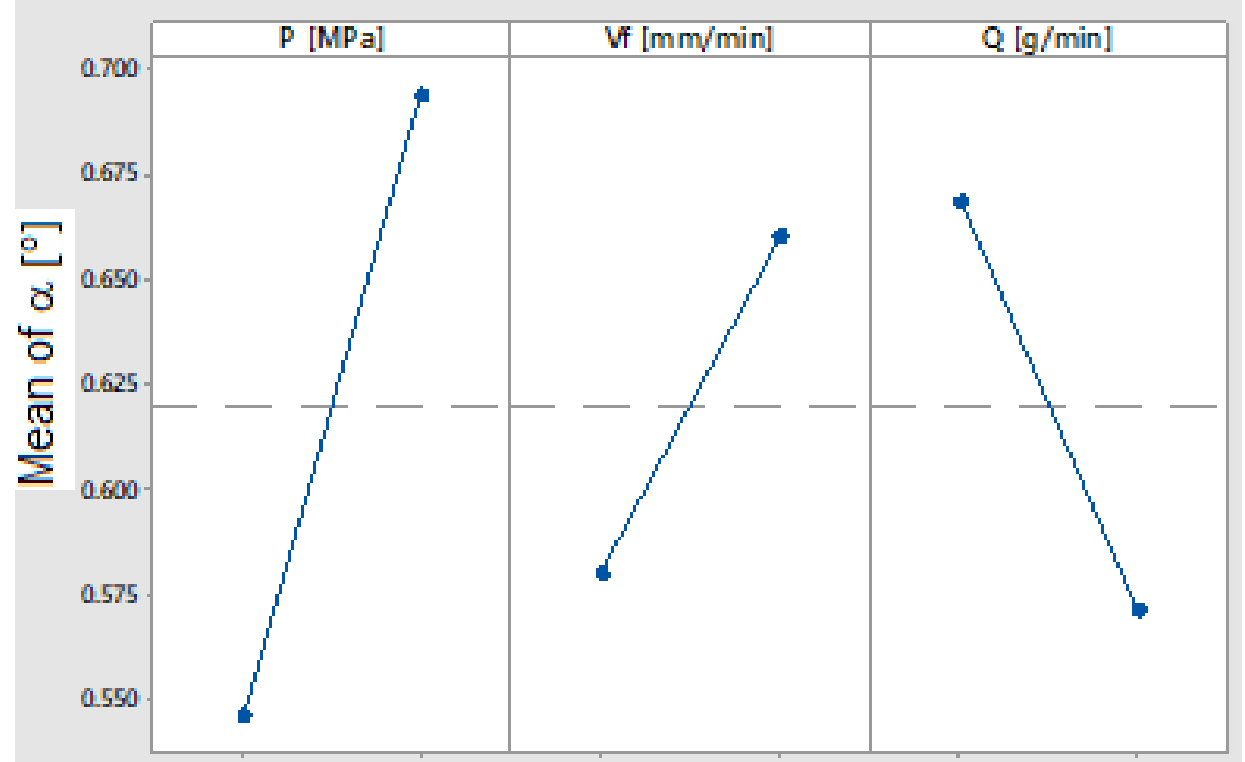

Fig. 3. Influence of parameters on the inclination angle of the machined surface from Arbofill Fichte

\subsection{Influence of technological parameters on the Arboblend V2 Nature}

\subsubsection{Amount of material removed - MR}

The data from the experimental plan were introduced in the MiniTab application with the help of which the ANOVA method was applied. Table 5 presents the results of this analysis which provides information on the influence of the analyzed parameters (pressure, traverse speed and abrasive material flow) on the amount of removed material (MR). the most significant influence was exerted by pressure (the value of the Fisher test - 45) followed by the "abrasive material flow" parameter - value of the Fisher test 23.95. The traverse speed has a much lower influence compared to the other two parameters. 
Table 5. The results of the variance analysis by the ANOVA method - MR parameter

\begin{tabular}{lcccc}
\hline Parameter & Freedom degrees & Adj SS & Adj MS & Fisher value \\
\hline Pressure [MPa] & 1 & 0.008596 & 0.008596 & 45 \\
\hline Traverse speed [mm/min] & 1 & 0.000245 & 0.000245 & 1,3 \\
\hline Abrasive material flow g/min] & 1 & 0.004528 & 0.004528 & 23,95 \\
\hline Error & 4 & 0.000756 & 0.000189 & \\
\hline Total & 7 & 0.014125 & & \\
\hline
\end{tabular}

where: Adj SS - Adjusted Sums of Squares; Adj MS - Adjusted Mean Squares.

The matrix model of the technological parameters influence on the amount of material removed is expressed by the following relation (3):

$M R=0.4698+\left[\begin{array}{c}-0.03278 \\ 0.03278\end{array}\right] \cdot P+\left[\begin{array}{c}0.00554 \\ -0.00554\end{array}\right] \cdot v_{f}+\left[\begin{array}{c}-0.02379 \\ 0.02379\end{array}\right] \cdot Q,[\mathrm{~g}]$

where P, vf and Q are the two-dimensional vectors of pressure, traverse speed and abrasive material flow, respectively:

$P=\left[\begin{array}{l}100 \\ 150\end{array}\right], v_{f}=\left[\begin{array}{l}100 \\ 150\end{array}\right]$ şi $Q=\left[\begin{array}{l}150 \\ 300\end{array}\right]$

The minimum value of the MR is $0.408 \mathrm{~g}$ for the following values of the technological parameters: $\mathrm{P}=100 \mathrm{MPa}$; $\mathrm{V}_{\mathrm{f}}=150 \mathrm{~mm} / \mathrm{min}$ and $\mathrm{Q}=150 \mathrm{~g} / \mathrm{min}$. The average of the presented model is $0.47 \mathrm{~g}$.

The graphical representation from figure 4 emphasizes the influence of each parameter on the amount of material removed in the case of Arboblend V2 Nature processing. The amount of material removed decreases with the reduction of the pressure and the flow of abrasive material; it also decreases with increasing traverse speed.

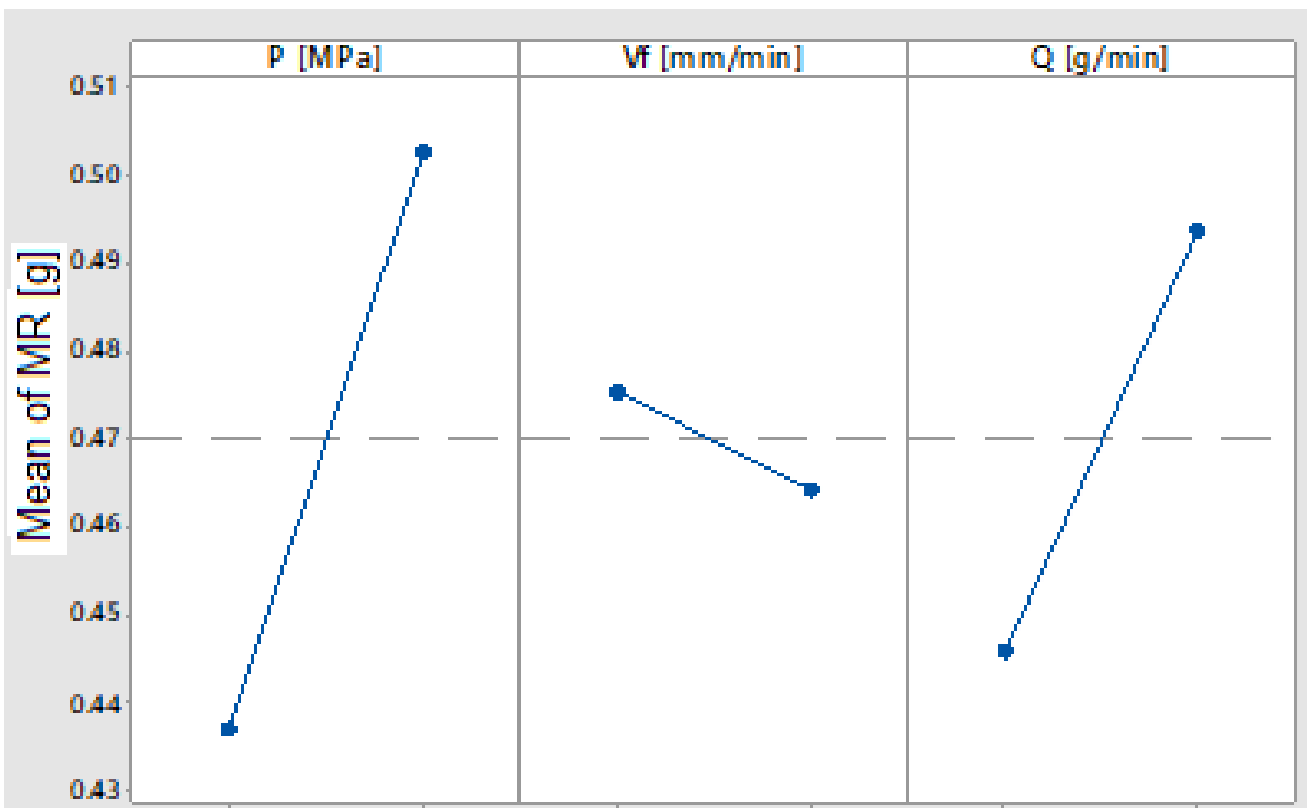

Fig. 4. Influence of parameters on the amount of material removed - samples from Arboblend V2 Nature

\subsubsection{Angle of inclination of the cutted surface $-\alpha^{\circ}$}

The results of the process parameters influence for the Arboblend V2 Nature lignin-based polymer are described in Table 6. The greatest influence on the inclination angle was exerted by the cutting pressure (Fisher test value - 1.57) followed by the abrasive material flow (Fisher test value - 1.01 ). The traverse speed has a very low influence. 
Table 6. The results of the variance analysis by the ANOVA method - inclination angle of the machined surface $\left(\alpha^{\circ}\right)$

\begin{tabular}{lcccc}
\hline Parameter & Freedom degrees & Adj S & Adj MS & Fisher value \\
\hline Pressure $[\mathrm{MPa}]$ & 1 & 0.103 & 0.1 & 1.57 \\
\hline Traverse speed $[\mathrm{mm} / \mathrm{min}]$ & 1 & 0.007 & 0.007 & 0.11 \\
\hline Abrasive material flow $[\mathrm{g} / \mathrm{min}]$ & 1 & 0.066 & 0.066 & 1.01 \\
\hline Error & 4 & 0.26 & 0.065 & \\
\hline Total & 7 & 0.44 & & \\
\hline
\end{tabular}

where: Adj SS - Adjusted Sums of Squares; Adj MS - Adjusted Mean Squares.

The linear matrix model of the technological parameters influence on the inclination angle is given by the regression relation (4):

$\alpha=0.7925+\left[\begin{array}{c}-0.1134 \\ 0.1134\end{array}\right] \cdot P+\left[\begin{array}{c}-0.0298 \\ 0.0298\end{array}\right] \cdot v_{f}+\left[\begin{array}{c}0.0907 \\ -0.0907\end{array}\right] \cdot Q,\left[^{\circ}\right]$

where $\mathrm{P}, \mathrm{V}_{\mathrm{f}}$ and $\mathrm{Q}$ are the two-dimensional vectors of pressure, traverse speed and abrasive material flow, respectively:

$Q=\left[\begin{array}{l}100 \\ 150\end{array}\right], v_{f}=\left[\begin{array}{l}100 \\ 150\end{array}\right]$ and $Q=\left[\begin{array}{l}150 \\ 300\end{array}\right]$

The minimum inclination angle is $\alpha=0.56^{\circ}$ obtained for the next values of the input parameters: $\mathrm{P}=100 \mathrm{MPa}$; $\mathrm{Vf}=100 \mathrm{~mm} / \mathrm{min}$; and $\mathrm{Q}=300 \mathrm{~g} / \mathrm{min}$. The mean $\alpha$ of the presented model is $0.79^{\circ}$.

Figure 5 graphically shows the influence of technological parameters on the inclination angle resulting from the cutting of Arboblend V2 Nature material. The inclination angle decreases with the reduction of pressure and traverse speed; the increase of the abrasive material flow determines the decrease of the inclination angle.

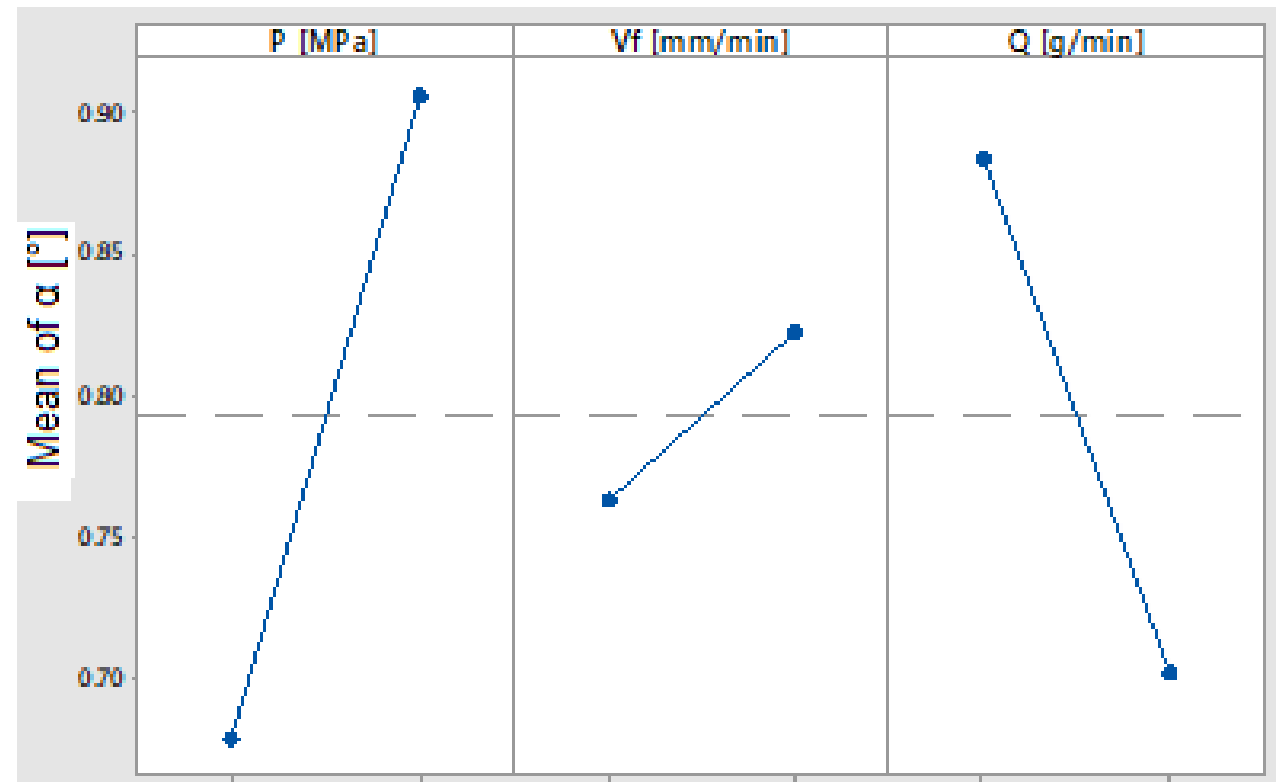

Fig. 5. Influence of parameters on the inclination angle of the machined surface from Arboblend V2 Nature

\section{CONCLUSIONS}

Determination of the material removed amount (MR) was realised on the basis of next relation: MR $=\rho /$ volume, $[\mathrm{g}]$, where the density $-\rho$ was measured using an analytical balance, at the calculated volume the width of the processed surface at the input of the jet was taken into account. $\left(L_{i}\right)$, the width of the surface processed at the output of the jet $\left(L_{o}\right)$ and the height $(g)$ of the isosceles trapezoid made by the water jet at the time of cutting, 
which coincides with the thickness of the material cut. The lowest value of the material removed amount during processing but also the lowest inclination angle was obtained for the experiment in which process parameters had the following values: pressure at first level of variation $-100 \mathrm{MPa}$, feed rate at first level of variation $100[\mathrm{~mm} / \mathrm{min}]$ and amount of abrasive material at second level of variation $-300 \mathrm{~g} / \mathrm{min}$, [8].

The average amount of material removed for the Arbofill Fichte biopolymer was $0.433 \mathrm{~g}$ and for the Arboblend V2 Nature material $0.47 \mathrm{~g}$. The cut was $30 \mathrm{~mm}$ long, $10 \mathrm{~mm}$ deep, $1.14 \pm 0.01 \mu \mathrm{m}$ in width and $0.95 \pm 0.01 \mu \mathrm{m}$ in width, [9].

The width of the machined surface at the abrasive jet input $\left(L_{i}\right)$ is higher than than the resulting width at the jet output $\left(L_{o}\right)$, which makes the cut take on a conical shape, in "V". In this sense, the deviation from the perpendicularity of the abrasive jet was determined by finding the inclination angle of the processed surface, the average values obtained for the two materials were: $0.62^{\circ}$ - Arbofill Fichte and $0.79^{\circ}$ - Arboblend V2 Nature. The taper of the cut was influenced by the cutting speed and the sample thickness, the higher their values, the higher the taper and, implicitly, the deviation from the perpendicularity will be. Also, the MR and $\alpha$ values for Arboblend V2 Nature material are higher due to its chemical structure, being a more rigid material than Arbofill Fichte and thus yielding faster under the influence of water jet pressure.

Determination of the abrasive water jet cutting behavior on the studied materials highlighted admissible values of the $\alpha$ and MR parameters thus, the parts obtained by this process and materials, can be used in industrial applications.

\section{REFERENCES}

1. Srikanth, Pilla, (2011). Handbook of bioplastics and Biocomposites Engineering Applications, Scrivener Publishing, LLC.

2. Dohertya W.O.S., Mousaviouna, P., Fellows, C.M., (2011). Value-adding to cellulosic ethanol: Lignin polymers, Industrial Crops and Products, 33(2), 259-276.

3. Mistodie, L.R., Ghiţă, E., MIRCEA O., (2007). Consideraţii tehnico-economice la tăierea cu jet de apă abraziv, Conferinţa internaţională Tehnologii inovative pentru îmbinarea materialelor avansate, ISIM Timişoara.

4. Guptaa, V., Pandeya, P.M., Mohinder Pal Garg, Khannab, R., Batrab, N.K., (2014). Minimization of kerf taper angle and kerf width using Taguchi's method in abrasive water jet machining of marble, Procedia Material Science, 6, 140-149.

5. Available from: https://www.tecnaro.de/, Accessed: 12/09/2021.

6. Mărguță, D., Herghelegiu, E., Tâmpu, C., Mazurchevici, S.-N., Nedelcu, D., (2021). Water jet cutting influence on lignin-based polymer samples, International Journal of Modern Manufacturing Technologies, XIII (1), 132-139.

7. Batra, P.K., Seema Jaggi, (2019). Factorial Experiments, Available from: https://www.coursehero.com/file/9170119/5-Factorial-Expts/, Accessed: 02/07/2021.

8. Marguta, D., Herghelegiu, E., Tampu, C., Mazurchevici, S.-N., Nedelcu, D., (2021). Behavior of Arboblend V2 Nature under AWJ machining, IOP Conference Series Materials Science and Engineering, 1182(1), 012044, DOI:10.1088/1757-899X/1182/1/012044.

9. Marguta, D., Herghelegiu, E., Tampu, C., Mazurchevici, S.-N., Nedelcu, D., (2021). Technological parameters influence on biodegradable injected polymers during water jet cutting, Journal of Engineering Sciences and Innovation, 6(3), 235 - 248.

Received: September 11, 2021 / Accepted: December 15, 2021 / Paper available online: December 20, 2021 () International Journal of Manufacturing Economics and Management. 